Article

\title{
Cyanobacteria Secondary Metabolites as Biotechnological Ingredients in Natural Anti-Aging Cosmetics: Potential to Overcome Hyperpigmentation, Loss of Skin Density and UV Radiation-Deleterious Effects
}

\author{
Rita Favas ${ }^{1,2}$, Janaína Morone ${ }^{1,2} \mathbb{D}$, Rosário Martins ${ }^{1,3} \mathbb{D}$, Vitor Vasconcelos ${ }^{1,2} \mathbb{D}$ and Graciliana Lopes ${ }^{1, *} \mathbb{D}$ \\ 1 CIIMAR/CIMAR, Interdisciplinary Centre of Marine and Environmental Research, Novo Edifício do \\ Terminal de Cruzeiros do Porto de Leixões, Avenida General Norton de Matos, S/N, \\ 4450-208 Matosinhos, Portugal; rita.favas@hotmail.com (R.F.); janabavini@ciimar.up.pt (J.M.); \\ mrm@ess.ipp.pt (R.M.); vmvascon@fc.up.pt (V.V.) \\ 2 FCUP, Department of Biology, Faculty of Sciences, University of Porto, Rua do Campo Alegre, \\ 4169-007 Porto, Portugal \\ 3 CISA, Health and Environment Research Centre, School of Health, Polytechnic Institute of Porto, \\ Rua Dr. António Bernardino de Almeida, 400, 4200-072 Porto, Portugal \\ * Correspondence: glopes@ciimar.up.pt
}

Citation: Favas, R.; Morone, J.; Martins, R.; Vasconcelos, V.; Lopes, G. Cyanobacteria Secondary Metabolites as Biotechnological Ingredients in Natural Anti-Aging Cosmetics: Potential to Overcome

Hyperpigmentation, Loss of Skin Density and UV Radiation-Deleterious Effects. Mar. Drugs 2022, 20, 183. https://doi.org/10.3390/md20030183

Academic Editor: Azadeh

Kermanshahi-Pour

Received: 7 February 2022

Accepted: 25 February 2022

Published: 1 March 2022

Publisher's Note: MDPI stays neutral with regard to jurisdictional claims in published maps and institutional affiliations.

Copyright: (C) 2022 by the authors. Licensee MDPI, Basel, Switzerland. This article is an open access article distributed under the terms and conditions of the Creative Commons Attribution (CC BY) license (https:// creativecommons.org/licenses/by/ $4.0 /)$.

\begin{abstract}
The loss of density and elasticity, the appearance of wrinkles and hyperpigmentation are among the first noticeable signs of skin aging. Beyond UV radiation and oxidative stress, matrix metalloproteinases (MMPs) assume a preponderant role in the process, since their deregulation results in the degradation of most extracellular matrix components. In this survey, four cyanobacteria strains were explored for their capacity to produce secondary metabolites with biotechnological potential for use in anti-aging formulations. Leptolyngbya boryana LEGE 15486 and Cephalothrix lacustris LEGE 15493 from freshwater ecosystems, and Leptolyngbya cf. ectocarpi LEGE 11479 and Nodosilinea nodulosa LEGE 06104 from marine habitats were sequentially extracted with acetone and water, and extracts were analyzed for their toxicity in cell lines with key roles in the skin context (HaCAT, 3T3L1, and hCMEC). The non-toxic extracts were chemically characterized in terms of proteins, carotenoids, phenols, and chlorophyll $a$, and their anti-aging potential was explored through their ability to scavenge the physiological free radical superoxide anion radical $\left(\mathrm{O}_{2}{ }^{--}\right)$, to reduce the activity of the MMPs elastase and hyaluronidase, to inhibit tyrosinase and thus avoid melanin production, and to block UV-B radiation (sun protection factor, SPF). Leptolyngbya species stood out for anti-aging purposes: L. boryana LEGE 15486 presented a remarkable SPF of 19 (at $200 \mu \mathrm{g} / \mathrm{mL}$ ), being among the best species regarding $\mathrm{O}_{2}{ }^{\bullet-}$ scavenging, $\left(\mathrm{IC}_{50}=99.50 \mu \mathrm{g} / \mathrm{mL}\right)$ and also being able to inhibit tyrosinase $\left(\mathrm{IC}_{25}=784 \mu \mathrm{g} / \mathrm{mL}\right)$, proving to be promising against UV-induced skin-aging; L. ectocarpi LEGE 11479 was more efficient in inhibiting MMPs (hyaluronidase, $\mathrm{IC}_{50}=863 \mu \mathrm{g} / \mathrm{mL}$; elastase, $\mathrm{IC}_{50}=391 \mu \mathrm{g} / \mathrm{mL}$ ), thus being the choice to retard dermal density loss. Principal component analysis (PCA) of the data allowed the grouping of extracts into three groups, according to their chemical composition; the correlation of carotenoids and chlorophyll $a$ with MMPs activity $(p<0.01), \mathrm{O}_{2}{ }^{\bullet-}$ scavenging with phenolic compounds $(p<0.01)$, and phycocyanin and allophycocyanin with SPF, pointing to these compounds in particular as responsible for UV-B blockage. This original survey explores, for the first time, the biotechnological potential of these cyanobacteria strains in the field of skin aging, demonstrating the promising, innovative, and multifactorial nature of these microorganisms.
\end{abstract}

Keywords: melanin; UV-blocker; elastase; hyaluronidase; tyrosinase; oxidative-stress; beta-carotene; phycocyanin; phycoerythrin; allophycocyanin 


\section{Introduction}

Skin is a large and surprisingly complex human organ with a primordial barrier function of protecting internal organs from harmful stressors, such as chemicals, pathogens, cold, heat, and ultraviolet radiation (UVR). However, the importance of the skin goes much further, encompassing an undeniable socio-cultural role. In fact, skin appearance and shape are of crucial importance to an individual's self-esteem, its care and beautification being part of the daily routine since ancient times [1].

The delay of the skin-aging process has been a main societal demand. This slow and complex process is induced by endogenous and exogenous factors that predispose skin to a progressive structural and functional degeneration that, beyond affecting its aesthetic appearance, leaves it prone to the development of a wide variety of diseases. Among exogenous factors, UVR is perhaps the most harmful agent to which the skin is most exposed. Excessive UVR exposure increases free radical generation, triggering a cascade of events that affect a wide variety of cell structures and enzymes, resulting in an immediate inflammatory response, and finally culminating in premature skin aging [2]. A particularly affected target in this theme is the extracellular matrix (ECM), a three-dimensional network of elastin and collagen fibers surrounded by the ground substances, such as hyaluronic acid (HA), that act together to maintain skin filling, elasticity, and flexibility [3]. Under a framework of oxidative-stress, elastin and collagen fibers, responsible for the elasticity and resistance of the skin, may lose their structure [4]. This phenomenon, partly due to the deregulated activity of the matrix metalloproteinases (MMPs), such as elastase, collagenase, and hyaluronidase, is at the base of premature skin aging associated with external factors [1]. These alterations affect the epidermal thickness, structure, and appearance, resulting in dryness, enlarged pores, fine lines, and wrinkles [5,6]. Therefore, the search for new, effective, multitarget, and innovative ingredients for cosmetic formulations able to reach the greatest number of key targets in the skin aging process has been the focus of the cosmetics industry in recent decades.

The growing research on natural sources, more specifically those of marine origin, has provided a countless number of new molecules with promising bioactivities, worthy of further exploitation in the field of skin aging [1]. Among them, cyanobacteria stand out due to their capacity to produce bioactive secondary metabolites with unique structures and mechanisms of action. Beyond representing the only group of prokaryotes that can perform oxygenic photosynthesis, similarly to plants, cyanobacteria are self-renewable, have basic nutritional requirements, require minimal cultivation space, and have a low environmental impact, being a sustainable choice as a green source of cosmetic ingredients [7].

Focusing on skin formulations, cyanobacteria produce a wide array of bioactive metabolites, including phenolic compounds, proteins, pigments, and MMPs inhibitors, that cover the main processes comprising the basis of skin aging, namely antioxidation, photoprotection, and the ability to inhibit crucial enzymes of the ECM [8-12], as recently reviewed $[1,9]$. Regarding antioxidant activity, numerous strains have been reported to have a representative amount of metabolites with radical scavenging capacity, such as carotenoids, e.g., those from the genera Leptolyngbya, Synechocystis, and Wollea [9,13], phycobiliproteins (PBP), such as Arthospira spp. and Spirulina spp. [13,14], and phenolic compounds, such as Nostoc commune [15]. In the field of photoprotection, cyanobacteria also stand out through the production of the well-known UVR-absorbing compounds mycosporine-like amino acids (MAAs) and scytonemin (SCY) [16]. Concerning the potential to inhibit collagenases, elastase, hyaluronidases, and tyrosinase, several examples are reported in the literature, such as mycosporine-2-glycine (M2G), isolated from the cyanobacterium Aphanothece halophytica [17], the cyclic depsipeptides tutuilamides A-C, from Schizothrix spp. and Coleofasciculus spp. [18], a polysaccharide from Nostochopsis lobatus MAC0804NAN [19], and the extract Phormiskin Bioprotech $\mathrm{G}^{\circledR}$, from Phormidium persicinum [20], respectively.

Despite the studies presented above, the number of cyanobacteria strains explored in the field of cosmetics is still very low, considering the potentialities of this resource. With this in mind, this survey explores, for the first time, the biotechnological potential of 
sequential extracts of different polarities, obtained from four cyanobacteria strains, in the field of skin aging, demonstrating the promising, innovative, and multifactorial nature of these microorganisms.

\section{Results and Discussion}

In the present study, two freshwater and two marine cyanobacteria strains were cultured, harvest, and subjected to a sequential extraction with acetone and water, with a view to their exploitation for cosmetic purposes. The sequential extraction with acetone followed by water was designed to monetize the biomass, in a more sustainable, environmentally friendly, and economically attractive process. In Table 1, the extraction yields are displayed.

Table 1. Cyanobacteria extraction yield $(\% w / w)$.

\begin{tabular}{ccc}
\hline \multirow{2}{*}{ Strains } & \multicolumn{2}{c}{ Solvent } \\
\cline { 2 - 3 } & Acetone & Water \\
\hline Nodosilinea nodulosa LEGE 06104 & 0.6 & 9.0 \\
Leptolyngbya cf. ectocarpi LEGE 11479 & 1.6 & 14.5 \\
Cephalothrix lacustris LEGE 15493 & 2.0 & 9.5 \\
Leptolyngbya boryana LEGE 15486 & 2.9 & 22.0 \\
\hline
\end{tabular}

The extraction yield was significantly higher with water than with acetone $(p<0.05)$, which has a direct correlation with the affinity of the different compounds to each solvent, their molecular weight, and polarity, as later discussed in this study. It should be noted that Leptolyngbya boryana LEGE 15486 was the strain which showed higher extraction yields, what could be economically interesting when considering possible industrial applications.

\subsection{Extracts Cytotoxicity}

In order to select the extracts to proceed for biological activities assessment, an in vitro cytotoxicity assay was performed using different cell lines. Cytotoxicity tests are essential during cosmetics production, since they may predict health risks connected with the use of the extracts as bioactive ingredients. Thus, the cytotoxicity of the extracts was evaluated in three different cell lines of key importance regarding products for skin application: keratinocytes (HaCat), fibroblasts (3T3L1), and endothelial cells (hCMEC). Fibroblasts are among the most important cells regarding skin aging, being responsible for the production of the dermal matrix components essential for the maintenance of skin shape and structure, such as collagen and hyaluronic acid $[9,21]$. Endothelial cells form a barrier between vessel walls and blood, and were chosen to account for their presence in the dermis which, contrary to the epidermis, is an irrigated layer of the skin [22]. Regarding keratinocytes, they are the key cells of the epidermis, composing about 95\% of this layer, but are present in all four layers, and provide structure and defense to the skin $[23,24]$. None of the extracts presented toxicity for the selected cell lines under the tested concentrations $(12.5-200 \mu \mathrm{g}$ dry extract $/ \mathrm{mL})$ (Figures S1-S3). In this regard, all the extracts followed to the next step, where they were subjected to chemical characterization and evaluation of their biological activities.

\subsection{Chemical Profile}

The acetone and water extracts were chemically characterized in terms of phenols, total proteins, PBPs, total carotenoids, and chlorophyll $a$, in order to compare the chemical profiles obtained with the different extraction solvents, and to establish a relationship between the chemical composition and the biological activities evaluated.

\subsubsection{Total Phenolic Content (TPC)}

The total phenolic content (TPC) of both extracts was measured through the FolinCiocalteu colorimetric assay. Even considering the inherent limitations of the method, this is a standard assay widely used for the quick determination of total phenols, allowing the 
comparison of different samples, and consequently predicting their antioxidant potential. Table 2 displays the data (expressed in GAEs) for the total phenolic content of the eight extracts explored in the present study. The highest TPC was found in the acetone extract of Leptolyngbya cf. ectocarpi LEGE 11479, with $17.59 \mu \mathrm{g} \mathrm{GAE} / \mathrm{mg}$ dry extract, followed by the water extracts of Leptolyngbya boryana LEGE 15486 and Cephalothrix lacustris LEGE 15493 (Table 2). Considering the yield of the combined extraction, Leptolyngbya cf. ectocarpi LEGE 11479 was the richest species, totaling about $26 \mu \mathrm{g} \mathrm{GAE} / \mathrm{mg}$ dry extract when considering both extraction solvents.

Table 2. Total phenolic content ( $\mu$ g GAE/mg dry extract) of cyanobacteria extracts ${ }^{1,2,3}$.

\begin{tabular}{ccc}
\hline \multirow{2}{*}{ Strains } & \multicolumn{2}{c}{ Solvent } \\
\cline { 2 - 3 } & Acetone & Water \\
\hline Nodosilinea nodulosa LEGE 06104 & $11.23 \pm 1.55$ & $6.52 \pm 0.38$ \\
Leptolyngbya cf. ectocarpi LEGE 11479 & $17.59 \pm 2.29$ & $8.49 \pm 1.18$ \\
Cephalothrix lacustris LEGE 15493 & nd & $13.75 \pm 0.28$ \\
Leptolyngbya boryana LEGE 15486 & $7.10 \pm 1.73$ & $13.98 \pm 0.90$ \\
\hline${ }^{1}$ GAE, gallic acid equivalents; ${ }^{2}$ Mean \pm SD of three independent experiments; ${ }^{3}$ nd, not detected.
\end{tabular}

Overall, the water extracts of the freshwater strains presented higher phenolic content than those from marine environments, while the opposite behavior was observed regarding acetone extracts. This observation was also noted for the two strains of the same genera, what leads to the assumption that, beyond species-specific characteristics, marine strains are more likely to produce phenolic compounds of lower polarity, given their higher prevalence in less polar solvents. Phenols have a polar and a nonpolar component in their molecules, possessing a solubility preference to solvents of intermediate polarities such as alcohols and acetone, rather than water. However, the solubility of phenols in different solvents cannot be based only on their polarities, since other parameters such as temperature and $\mathrm{pH}$ can have a great influence on their solubility, and thus justify their expressive presence in water extracts [25].

Previous work from our research group also explored TPC in different cyanobacteria extracts. Morone and co-workers [26] used the same methodology for TPC quantification, and found that Nodosilinea nodulosa LEGE 06102 had a value of $1.23 \mathrm{mg}$ GAE/g dry biomass, which was above the values obtained herein $(0.59 \mathrm{mg}$ GAE $/ \mathrm{g}$ dry biomass, converted according to the extraction yield). However, the authors used $70 \%$ ethanol as an extraction solvent, which certainly led to the differences observed. For all the strains analyzed by the authors, the highest value was found in Synechocystis salina LEGE 06099 (2.45 mg GAE/g). In another study, with Nodosilinea antarctica LEGE 13457, the TPC content was $19.23 \mu \mathrm{g}$ GAE/mg (acetone extract) and no phenols were detected in Leptolyngbya-like sp. LEGE 13412, which demonstrated the highest variability among similar species. They also reported data for other strains, with Cyanobium gracile LEGE 12431 presenting the highest phenol content, with $22.01 \mu \mathrm{g} \mathrm{GAE} / \mathrm{mg}$ of acetone extract [27]. Trabelsi and his team [28] reported that the thermophilic cyanobacterium Leptolyngbya sp. possessed $139 \mathrm{mg}$ GAE/g, this being the among the highest values reported in the literature, and attributed by the authors to the high temperature of the cyanobacterial habitat: to avoid oxidative stress induced by high temperatures, cyanobacteria produce higher amounts of antioxidant compounds such as phenols and flavonoids. Another research group [29] also reported a TPC of $6.24 \mathrm{mg}$ GAE/g for Leptolyngbya sp. KC45, sampled from a location with temperatures of approximately $40-45^{\circ} \mathrm{C}$.

Despite the differences inherent to the effects of the extraction solvents, and to the cyanobacterial cultivation conditions, such as light conditions, culture medium nutrients, and cell density, among others, the TPC values obtained herein are within the same order of magnitude as those reported in the literature. Moreover, Leptolyngbya boryana LEGE 15486 can be pointed out as an interesting species regarding phenolic com- 
pounds (3.08 mg GAE/g dry biomass), when compared to the widely known Spirulina spp. (1.78 $\mathrm{mg} \mathrm{GAE} / \mathrm{g})[30]$.

\subsubsection{Proteins}

Although proteins are generally undervalued, they compose a large fraction of the cyanobacterial biomass [31], with reported antioxidant and immunostimulant properties, as well as the ability to confer moisture retention to the skin, which is essential to prevent skin aging [32]. With this in mind, the extracts explored in the present study were characterized for their protein content, through a general approach focusing on total proteins (acetone and water extracts) (Table 3), and a targeted approach focusing on PBPs (water extracts) (Table 4).

Table 3. Total protein content ( $\mu \mathrm{g}$ BSA $/ \mathrm{mg}_{\text {dry extract }}$ ) in cyanobacteria extracts ${ }^{1}$.

\begin{tabular}{ccc}
\hline \multirow{2}{*}{ Strains } & \multicolumn{2}{c}{ Solvent } \\
\cline { 2 - 3 } & Acetone & Water \\
\hline Nodosilinea nodulosa LEGE 06104 & $134.76 \pm 2.41$ & $169.18 \pm 2.21$ \\
Leptolyngbya cf. ectocarpi LEGE 11479 & $136.63 \pm 3.60$ & $185.69 \pm 0.78$ \\
Cephalothrix lacustris LEGE 15493 & $218.23 \pm 3.48$ & $521.18 \pm 0.60$ \\
Leptolyngbya boryana LEGE 15486 & $177.27 \pm 5.89$ & $314.60 \pm 5.90$ \\
\hline
\end{tabular}

${ }^{1}$ Values are expressed as the mean \pm SD of three determinations.

Table 4. Phycobiliprotein content $\left(\mu \mathrm{g} / \mathrm{mg}_{\text {dry extract }}\right)$ in cyanobacteria aqueous extracts ${ }^{1}$.

\begin{tabular}{cccc}
\hline \multirow{2}{*}{ Strain } & \multicolumn{3}{c}{ Phycobiliprotein } \\
\cline { 2 - 4 } & Phycocyanin & Allophycocyanin & Phycoerythrin \\
\hline Nodosilinea nodulosa LEGE 06104 & $50.11 \pm 0.26$ & $10.14 \pm 0.60$ & $6.20 \pm 0.08$ \\
Leptolyngbya cf. ectocarpi LEGE 11479 & $53.94 \pm 0.24$ & $8.77 \pm 1.05$ & $138.73 \pm 0.33$ \\
Cephalothrix lacustris LEGE 15493 & $115.03 \pm 0.40$ & $27.85 \pm 0.16$ & $18.93 \pm 0.03$ \\
Leptolyngbya boryana LEGE 15486 & $154.07 \pm 0.26$ & $46.43 \pm 0.06$ & $7.51 \pm 0.09$ \\
\hline
\end{tabular}

${ }^{1}$ Values are expressed as the mean \pm SD of two determinations.

Regarding total proteins, it can be concluded that the aqueous extraction resulted in higher values than the acetone extraction, and also, that marine strains were poorer than those from freshwater environments. In terms of dry biomass, Leptolyngbya boryana LEGE 15486 presented the highest content (69.22 mg BSA/g dry biomass), and Nodosilinea nodulosa LEGE 06104 the lowest one (15.23 BSA/g dry biomass). Among other factors, these differences may be due to the different amount of structural proteins presented by different cyanobacteria strains [32].

A practical example of the use of proteins in cosmetics concerns PBSs, which are naturally present in cyanobacteria. One of cyanobacteria's defensive mechanisms is the capacity of these macromolecules to absorb light energy without producing reactive oxygen species (ROS), which is possible due to the changes in their content and ratio in phycobilisomes [33]. PBPs are water-soluble proteins that are associated with phycobilins, and divided into three groups according to their structure and light absorption spectra: phycocyanin (PC, 610-625 nm), phycoerythrin (PE, 490-570 nm), and allophycocyanin (APC, 650-660 nm). As stated earlier, their interest as cosmetic ingredients is mainly due to their recognized antioxidant potential, thanks to their structural resemblance to bilirubin, which eliminates oxygen derivatives. PC is the most common PBP in cyanobacteria, with interesting antioxidant and radical scavenging properties, as well as the capacity to inhibit cell proliferation $[13,14]$.

Regarding PC, Leptolyngbya boryana LEGE 15486 possessed the highest content $(154.07 \mu \mathrm{g} / \mathrm{mg}$ dry extract), followed by Cephalothrix lacustris LEGE $15493(115.03 \mu \mathrm{g} / \mathrm{mg}$ dry extract), which is in accordance with the strong blue color observed in the aqueous extracts of these species. On the other hand, Leptolyngbya cf. ectocarpi LEGE 11479, with an intense 
pink/purple coloration in the biomass and in the aqueous extract, was the richest in PE $(138.73 \mu \mathrm{g} / \mathrm{mg}$ dry extract). Nodosilinea nodulosa LEGE 06104, with the lightest blue extract, presented visibly lower values of both PBPs (Table 4).

When comparing strains in terms of PBPs, it is extremely important to consider the culture conditions because differences in light, nitrogen, temperature, $\mathrm{pH}$, carbon, and salinity can drastically influence their production [14]. Pumas and co-workers [29] evaluated the PBP content of the thermotolerant cyanobacteria Leptolyngbya sp. KC45, and found a PE content of almost $100 \mathrm{mg} / \mathrm{g}$, followed by approximately 40 and $43 \mathrm{mg} / \mathrm{g}$ of APC and PC, respectively, which is in line with the results obtained herein for Leptolyngbya cf. ectocarpi LEGE 11479 (Table 4). The work performed by Pagels and co-workers also explored the content of PBPs in sequential extracts obtained with different solvents. Although exploring a different cyanobacteria strain (Cyanobium sp.), the authors found a total PBP content close to $200 \mathrm{mg} / \mathrm{g}$ in a sequential extraction using the same solvents as those used herein, which is in accordance with the values obtained by us [34]. When comparing with the widely known Spirulina sp., with reported total PBPs of about $19 \mathrm{mg} / \mathrm{g}$ dry biomass [30], it is possible to consider our strains of economic interest. In the same study, the authors also reported values of $127.01 \mathrm{mg} / \mathrm{g}$ dry biomass of total PBPs for Lyngbya sp. In another study, data were presented from 18 strains, where the highest amount was found in Anabaena NCCU-9, with a value of $91.54 \mathrm{mg} / \mathrm{g}$ dry biomass [35].

\subsubsection{Carotenoids and Chlorophyll $a$}

Carotenoids are natural fat-soluble isoprenoids with a wide array of colorations, varying from yellow to red [13]. These compounds have gained increased attention for their association with a decreased risk of several degenerative disorders, and for their recognized antioxidant activity, partly related to the $\mathrm{C}=\mathrm{C}$ chemical double bonds present in their molecules. Besides these functions, carotenoids act as UV filters by reducing light exposure [36]. Some cyanobacteria such as Wollea vaginicola, Leptolyngbya foveolarum, and Synechocystis salina LEGE 06099 have been highlighted for their significant carotenoid content, enhancing their interest in the pharmacological and cosmetic fields $[9,13]$.

The total carotenoid and chlorophyll $a$ contents of the cyanobacteria acetone extracts explored herein are displayed in Table 5. The carotenoid amount ranged from 89 to $159 \mu \mathrm{g} / \mathrm{mg}$ dry extract, Leptolyngbya boryana LEGE 15486 being the richest strain. Regarding chlorophyll $a$, all the strains presented values greater than $100 \mu \mathrm{g} / \mathrm{mg}$ dry extract, with Cephalothrix lacustris LEGE 15493 standing out.

Table 5. Carotenoid and chlorophyll a content $(\mu \mathrm{g} / \mathrm{mg}$ dry extract) in the cyanobacteria acetone extracts ${ }^{1}$.

\begin{tabular}{ccc}
\hline Strains & \multicolumn{2}{c}{ Compounds } \\
& Carotenoids & Chlorophyll $\boldsymbol{a}$ \\
\hline Nodosilinea nodulosa LEGE 06104 & $125.34 \pm 5.0$ & $117.89 \pm 4.86$ \\
Leptolyngbya cf. ectocarpi LEGE 11479 & $89.07 \pm 5.0$ & $114.25 \pm 2.73$ \\
Cephalothrix lacustris LEGE 15493 & $137.50 \pm 2.8$ & $264.94 \pm 11.84$ \\
Leptolyngbya boryana LEGE 15486 & $159.39 \pm 5.0$ & $190.02 \pm 6.38$ \\
\hline
\end{tabular}

${ }^{1}$ Values are expressed as the mean \pm SD of three determinations.

Other cyanobacteria have also been the subject of pigment evaluation. For instance, Lopes and her team [27] reported $63.9 \mu \mathrm{g} / \mathrm{mg}$ dry extract of total carotenoids and $417.6 \mu \mathrm{g} / \mathrm{mg}$ dry extract of total chlorophylls for Nodosilinea antarctica LEGE 13457 acetone extract. The authors also provided data for Leptolyngbya-like sp. LEGE $13412(33.6 \mu \mathrm{g} / \mathrm{mg}$ dry extract $)$, and in both cases, the carotenoid amount was below the values reported herein. It is worth mentioning that, in the work referred to above, carotenoids were profiled by HPLC and thus, despite species-specific characteristics, the methodology justifies the differences obtained. Regarding chlorophylls, the amount reported by the authors was greater than that obtained herein, 
which is easily justified by the fact that they present the value of total chlorophylls, whereas the work herein focuses solely on chlorophyll a and its derivatives.

Another study from our research group reported a total of $0.37 \mathrm{mg} / \mathrm{g}$ dry biomass of carotenoids for the ethanol extract of Nodosilinea nodulosa LEGE 06102 [26], which was below the values obtained herein $(0.75 \mathrm{mg} / \mathrm{g}$ dry biomass, converted based on the extraction yield). This difference is certainly correlated with the solvent used in the extraction since, due to their chemical characteristics, carotenoids have a higher affinity for acetone. Generally speaking, the results obtained herein are within the same order of magnitude as those obtained by other authors, what may be explained by the very similar culture conditions and methodologies used.

\subsection{Biological Activities}

\subsubsection{Radical Scavenging Activity}

The superoxide anion radical is a physiological free radical with extreme importance for human body. When there is an overproduction of this ROS during aerobic respiration, or when the endogenous detoxification mechanisms fail or are insufficient, there is an increased risk of oxidative damage with serious deleterious effects. In this sense, finding mechanisms to inhibit the deleterious effects of $\mathrm{O}_{2}{ }^{\bullet-}$ is of key importance, not only in the field of cosmetics, but also considering the amelioration and prevention of a wide array of diseases. The $\mathrm{O}_{2}{ }^{\bullet-}$ scavenging behavior of cyanobacteria extracts is displayed in Figure 1, and the IC values are summarized in Table 6.

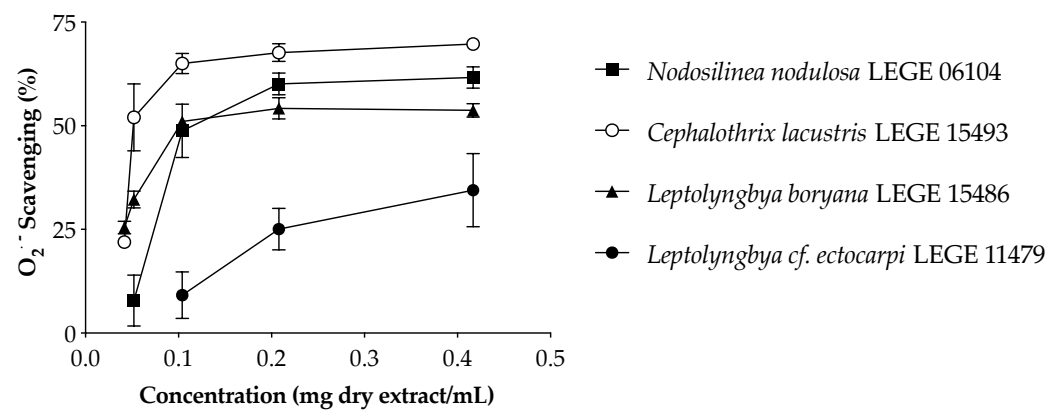

Figure 1. Superoxide anion radical $\left(\mathrm{O}_{2}{ }^{\bullet-}\right)$ scavenging activity of cyanobacteria aqueous extracts. Values are expressed as the mean $\pm \mathrm{SD}$ of three determinations.

Table 6. Inhibitory concentration (IC) values ( $\mu \mathrm{g}_{\text {dry extract }} / \mathrm{mL}$ ) of cyanobacteria extracts obtained for superoxide anion radical scavenging ${ }^{1}$.

\begin{tabular}{ccccc}
\hline \multirow{2}{*}{ Strains } & \multicolumn{3}{c}{ Solvent } \\
\cline { 2 - 5 } & \multicolumn{2}{c}{ Acetone } & Water & IC $_{\mathbf{2 5}}$ \\
\hline & $\mathbf{I C}_{\mathbf{2 5}}$ & $\mathbf{I C}_{\mathbf{5 0}}$ & $73.0 \pm 4.0$ & $101.3 \pm 22.9$ \\
\hline Nodosilinea nodulosa LEGE 06104 & $1121.50 \pm 89.80$ & - & - \\
Leptolyngbya cf. ectocarpi LEGE 11479 & $580.0 \pm 29.7$ & $1190.5 \pm 108.2$ & $42.5 \pm 0.5$ & $65.5 \pm 7.8$ \\
Cephalothrix lacustris LEGE 15493 & $1080.0 \pm 254.9$ & - & $43.0 \pm 0.0$ & $99.5 \pm 0.7$ \\
Leptolyngbya boryana LEGE 15486 & $1190.3 \pm 110.8$ & - & $198.7 \pm 23.3$ &
\end{tabular}

${ }^{1}$ Values are expressed as the mean \pm SD of three determinations.

The aqueous extracts were significantly more effective in $\mathrm{O}_{2}{ }^{\bullet-}$ scavenging than the acetone extracts (Table 6) and presented a dose-dependent activity (Figure 1), with the freshwater strains standing out from the marine strains. Cephalothrix lacustris LEGE 15493 was the most effective strain, presenting the lowest $\mathrm{IC}_{50}$ value $(65.5 \mu \mathrm{g}$ dry extract $/ \mathrm{mL}$, $p<0.05)$, followed by Leptolyngbya boryana LEGE 15486 and Nodosilinea nodulosa LEGE 06104. Leptolyngbya cf. ectocarpi LEGE 11479 was the only strain which did not reach the $\mathrm{IC}_{50}$ for the aqueous extract (Table 6). On the other hand, the acetone extract of this strain was the most effective in $\mathrm{O}_{2}^{\bullet-}$ scavenging.

A comparison of the antioxidant capacities among different cyanobacteria is challenging due to the different methods applied. Morone and co-workers evaluated the radical 
scavenging ability of ethanol $(70 \% v / v)$ extracts of different cyanobacteria strains [26], the lowest $\mathrm{IC}_{50}$ value being $822.70 \mu \mathrm{g} / \mathrm{mL}$ for Phormidium sp. LEGE 05292, while no activity was detected for Nodosilinea nodulosa LEGE 06102. Lopes and co-workers reported $\mathrm{O}_{2}{ }^{\bullet-}$ scavenging activity for Nodosilinea (Leptolynbbya) antarctica LEGE13457 and Cuspidothrix issatschenkoi LEGE 03282 acetone extracts, with $\mathrm{IC}_{25}$ values of 319 and $286 \mu \mathrm{g} / \mathrm{mL}$, and no activity for Leptolynbbya-like sp. LEGE 13412 [27]. The authors also reported a higher effectiveness in the acetone extracts when compared to ethanol extracts. Another study conducted by Amaro and co-workers revealed IC $_{50}$ values of 1394 and $826 \mu \mathrm{g} / \mathrm{mL}$ for Gloeothece sp. and Scenedesmus obliquus (M2-1), respectively [37]. The results obtained herein for acetone extracts seem less promising than those previously reported, even though they are within the same order of magnitude. On the other hand, the aqueous extracts revealed an enormous potential worthy of further exploitation regarding cosmetic applications in the field of skin aging.

\subsubsection{Enzymes Inhibition}

MMPs are a family of extracellular zinc-dependent enzymes, whose main function is to remodel and degrade the ECM [38], a gel-like material essential to hold cells together and provide a pathway for nutrients and oxygen [39]. Alterations in the ECM components, such as collagen and elastin, induced by MMPs are the basis of skin damage and wrinkle formation [40]. Together with these enzymes, linked with skin structure and wrinkle formation, another assumes a crucial role in the aging process due to its activity in melanogenesis: tyrosinase. Among other factors, UVR exposure causes an accumulation of an abnormal amount of melanin, due to increased ROS production. These reactive species affect the activity of melanocytes, which increases the conversion of tyrosine into melanin by oxidation, leading to hyperpigmentation and irregular skin patches [41].

In the search for natural alternatives to commercial anti-aging ingredients, focusing the enzymes mentioned above, the activity of cyanobacteria extracts was explored (Figure 2). Regarding HAase, only three strains were able to inhibit this enzyme, acting in a dose-dependent manner: the aqueous extract of Leptolyngbya cf. ectocarpi LEGE 11479 $\left(\mathrm{IC}_{50}=863 \mu \mathrm{g} / \mathrm{mL}\right)$, and the acetone extracts of Cephalothrix lacustris LEGE 15493 and Nodosilinea nodulosa LEGE 06104, the latter two only reaching $\mathrm{IC}_{25}$ (832 and $995 \mu \mathrm{g} / \mathrm{mL}$, respectively). Even though these values seem high, their range of activity was similar to that of the reference drug di-sodium cromoglicate (DSCG) $\left(\mathrm{IC}_{50}=1105 \mu \mathrm{g} / \mathrm{mL}\right)$. Moreover, it is worth mentioning that, for the highest concentration tested $(1 \mathrm{mg} / \mathrm{mL})$, Leptolyngbya cf. ectocarpi LEGE 11479 inhibited this enzyme in 80\% (Figure 2), which makes this extract promising as a cosmetic ingredient.

Few studies have reported on the potential effect of cyanobacteria compounds and extracts on hyaluronidase activity, and any comparison on extracts' biological potential should take into account that cyanobacterial metabolism suffers significant variation depending on the cultivation conditions, influencing extracts' chemical composition. Morone and co-workers [26] evaluated the effect of ethanol extracts of Tychonema sp. LEGE 07196 and Cyanobium sp. LEGE 07175 on hyaluronidase, and found a stronger inhibitory activity, with $\mathrm{IC}_{50}$ values of 182.74 and $208.36 \mu \mathrm{g} / \mathrm{mL}$, respectively. The activity of ethanol extracts has also been reported for an insoluble fraction of Spirulina platensis, with an $\mathrm{IC}_{50}$ of $150 \mu \mathrm{g} / \mathrm{mL}$ [42]. Another study, conducted by Yamaguchi and Koketsu [19], showed that Nostochopsis lobatus MAC0804NAN produced a large amount of polysaccharides with a high inhibitory effect $\left(\mathrm{IC}_{50}=7.18 \mu \mathrm{g} / \mathrm{mL}\right)$. It was also reported that an Arthrospira-derived peptide may be involved in hyaluronidase inhibition [43]. Together, these results support the potential of cyanobacteria compounds and extracts as anti-aging ingredients for cosmeceutical applications. 


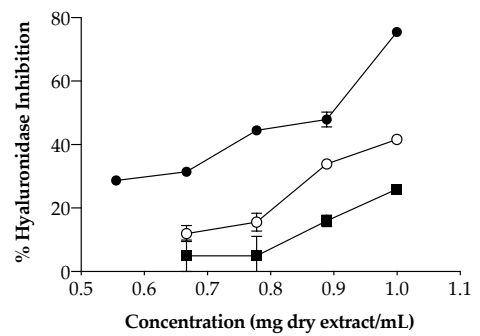

-- Leptolyngbya cf. ectocarpi LEGE 11479

- Nodosilinea nodulosa LEGE 06104

-o- Cephalothrix lacustris LEGE 15493

- Leptolyngbya boryana LEGE 15486
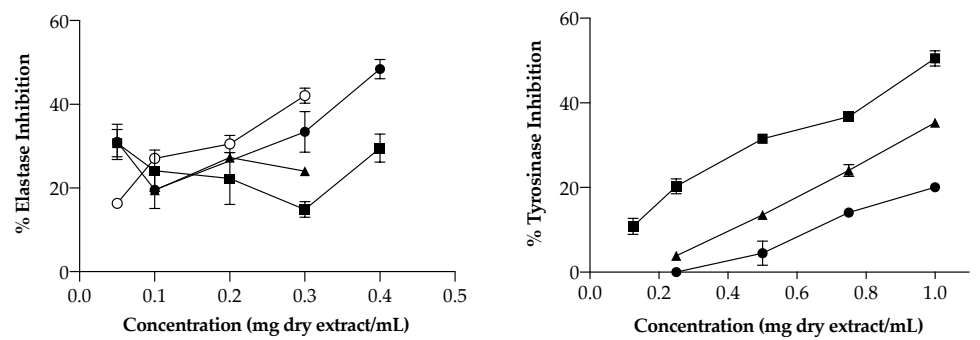

Figure 2. Inhibitory activity of cyanobacteria acetone extracts over the enzymes hyaluronidase, elastase, and tyrosinase. Values are expressed as the mean \pm SD of three determinations. The behavior of Leptolyngbya cf. ectocarpi LEGE 11479 on hyaluronidase corresponds to the aqueous extract.

Considering elastase, only acetone extracts presented interesting bioactivity. Leptolyngbya cf. ectocarpi LEGE 11479 was again the most active (Figure 2), being the only strain to reach the $\mathrm{IC}_{50}$, with a value of $391 \mu \mathrm{g} / \mathrm{mL}$. Nodosilinea nodulosa LEGE 06104, Cephalothrix lacustris LEGE 15493, and Leptolyngbya boryana LEGE 15486 only reached $\mathrm{IC}_{25}$, with values of 126,86 , and $99 \mu \mathrm{g} / \mathrm{mL}$, respectively. As for hyaluronidase, marine strains have shown to be the most promising.

To the best of our knowledge, there are no previous reports on elastase inhibitory activity for the strains explored herein. Regarding other strains, it was discovered that Nostoc minutum produced microviridins-type peptides and nostopeptins, with $\mathrm{IC}_{50}=1.3$ and $11.0 \mu \mathrm{g} / \mathrm{mL}$ [44,45]. Microviridins B and C obtained from Microcystis aeruginosa also inhibited elastase effectively, with $\mathrm{IC}_{50}$ values of 0.044 and $0.084 \mu \mathrm{g} / \mathrm{mL}$ [46]. Most of the available data regarding elastase inhibition focus on isolated compounds, so comparisons with the extracts from our strains are difficult to make.

Uneven skin pigmentation, associated with both aging and UV exposure, remains a major concern of aging populations and cosmetic industries. The majority of the available studies are trifling and use mushroom tyrosinase as an enzymatic model, making it difficult to translate the results to the human environment, nevertheless, this enzyme has a high similarity and homology with human tyrosinase [47]. Thus, the same enzymatic model was used herein to explore the potential of cyanobacteria extracts in tyrosinase inhibition. As for elastase, only acetone extracts were able to inhibit tyrosinase. Nodosilinea nodulosa LEGE 06104 was the most effective (Figure 2), being the only strain to reach the $\mathrm{IC}_{50}$ $(989.26 \pm 4.3 \mu \mathrm{g} / \mathrm{mL})$. Below that was Leptolyngbya boryana LEGE 15486, with $\mathrm{IC}_{25}=784$. $78 \pm 4.33 \mu \mathrm{g} / \mathrm{mL}$, and lastly Leptolyngbya cf. ectocarpi LEGE 11479, with the most promising results being found for the marine strains.

Morone and co-workers [26] previously explored the activity of cyanobacteria ethanolic extracts in the same model, but found no activity. One interesting aspect of this is that one of the studied strains was Nodosilinea nodulosa LEGE 06102, which showed the best results herein, once again emphasizing the importance of the extraction solvents in obtaining targeted bioactive extracts. As for the other enzymes explored, surveys focusing cyanobacteria are also scarce for tyrosinase. In work conducted by Yabuta and his team [48], it was reported that the hot water extract of Nostochopsis spp. significantly inhibited the tyrosinase activity $\left(\mathrm{IC}_{50}=250 \mu \mathrm{g} / \mathrm{mL}\right)$. This is a very interesting result, considering that it results from an aqueous extract, for which no activity was found in the present study. The authors attribute the result to the low molecular weight compounds released from 
PBPs by heat treatment, namely a biline moiety that acts as a potent peroxyl radical scavenger. Another study evaluated the inhibitory activity of Arthrospira platensis ethanol $\left(\mathrm{IC}_{50}=14,000 \mu \mathrm{g} / \mathrm{mL}\right)$ and water $\left(\mathrm{IC}_{50}=72,000 \mu \mathrm{g} / \mathrm{mL}\right)$ extracts, where the values were attributed to the presence of phenolic compounds such as ferulic and caffeic acids in the ethanol extract [49].

\subsubsection{UV Protection}

Even though a growing number of cosmetic companies incorporate sun blockers into their products, it is still difficult to convince consumers about the benefits of their daily use to slow down premature skin aging. If on the one hand, the daily application of sun blockers is a little ingrained habit, on the other hand, there is a certain fear in the use of synthetic substances, due to their unwelcome associated risks [50]. Following on from this, research on natural photoprotectors has considerably increased in the last few years, considering their potential for biodegradability and lower toxicity, making them more beneficial to humans and the environment. In order to explore cyanobacteria extracts in this field, their capacity to act as sunscreens was evaluated in vitro for UVR-B, since it is the most harmful radiation. The results found for cyanobacteria aqueous and acetone extracts are presented in Table 7.

Table 7. Sun protection factor of cyanobacteria extracts ${ }^{1}$.

\begin{tabular}{ccccc}
\hline \multirow{2}{*}{ Strains } & \multicolumn{3}{c}{ Solvent } \\
\cline { 2 - 5 } & \multicolumn{2}{c}{ Acetone } & \multicolumn{2}{c}{ Water } \\
\cline { 2 - 5 } & $\mathbf{2 0 0} \boldsymbol{\mu \mathbf { g } / \mathbf { m L }}$ & $\mathbf{1 0 0 0} \boldsymbol{\mu \mathbf { g } / \mathbf { m L }}$ & $\mathbf{2 0 0} \mathbf{\mu g} / \mathbf{m L}$ & $\mathbf{1 0 0 0} \boldsymbol{\mu g} / \mathbf{m L}$ \\
\hline Nodosilinea nodulosa LEGE 06104 & $3.50 \pm 0.07$ & $6.30 \pm 0.09$ & $1.30 \pm 0.02$ & $7.27 \pm 0.05$ \\
Leptolyngbya cf. ectocarpi LEGE 11479 & $10.74 \pm 0.41$ & $7.44 \pm 0.15$ & $1.97 \pm 0.02$ & $11.54 \pm 0.00$ \\
Cephalothrix lacustris LEGE 15493 & $7.79 \pm 0.51$ & $5.06 \pm 0.16$ & $2.87 \pm 0.02$ & $14.86 \pm 0.42$ \\
Leptolyngbya boryana LEGE 15486 & $19.22 \pm 1.50$ & $12.00 \pm 0.78$ & $3.05 \pm 0.16$ & $17.16 \pm 0.02$ \\
\hline
\end{tabular}

${ }^{1}$ Values are expressed as the mean \pm SD of three determinations.

Regarding acetone extracts, the most promising value (19.2) was found for Leptolyngbya boryana LEGE 15486, followed by Leptolyngbya cf. ectocarpi LEGE 11479 (10.7), both at the lowest concentration tested, $200 \mu \mathrm{g} / \mathrm{mL}$. Nodosilinea nodulosa LEGE 06104 was the least promising among acetone extracts. In aqueous extracts, the most promising results were obtained for the highest concentration tested, with Leptolyngbya boryana LEGE 15486 and Cephalothrix lacustris LEGE 15493 standing out with in vitro SPF values of 17.1 and 14.9, respectively (Table 7). Discussing previous studies in this field, Hossain and his team [51] reported that the SPF value for Cephalothrix komarekiana extract was 2.37. Another group found that the SPF of a methanol extract of Aphanizomenon flos-aquae was 4 [52]. However, the information about the concentration of the extract used by the authors was not available, making possible comparisons difficult.

The number of cyanobacteria strains explored in the field of cosmetics, especially regarding SPF, is very scarce, considering the potentialities of these resources. The results presented herein demonstrate that the species under study may be good options as biological photoprotectors, and possibly act as boosters to other sunscreens currently marketed, allowing a reduction in the concentration of synthetic sunscreens in the formulas. Therefore, it is crucial to increase research on these organisms, especially their bioactive extracts, that, being of significantly lower cost, higher yield, and faster obtainment than isolated compounds are more environmentally friendly and economically more attractive.

\subsection{Discrimination of Cyanobacteria Extracts by PCA Analysis}

The search for bioactive compounds from natural sources, with the potential for use as ingredients in the field of cosmetics has grown in recent years. In addition to being potentially less toxic and completely biodegradable, cyanobacteria-derived compounds are available from renewable sources and can be obtained at low cost in a controlled environment. The classification of bioactive extracts according to their chemical composition 
and biological activities can be valuable to point out potential relationships. In this regard, principal component analysis (PCA) was applied, considering the chemical composition of cyanobacteria extracts and the bioactivity of the highest concentration tested in each assay (Figure 3). As can be observed, $72.99 \%$ of the variability could be explained by the first two dimensions: PC1 accounted for $50.41 \%$ of the variance, while PC2 was responsible for $22.58 \%$. Three groups were distinguished (Figure 3A): G1, involving the Leptolyngbya cf. ectocarpi LEGE 11479 water extract; G2, involving the Cephalothrix lacustris LEGE 15493, Leptolyngbya boryana LEGE 15486 and Nodosilinea nodulosa LEGE 06104 water extracts; and G3, involving all the acetone extracts.

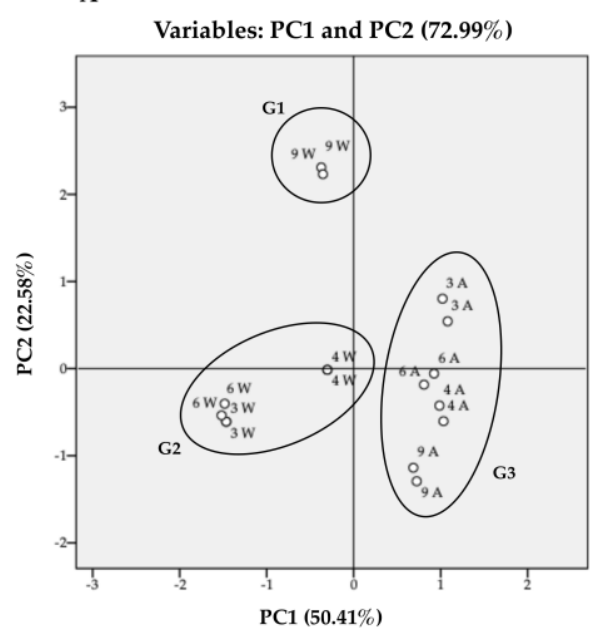

B

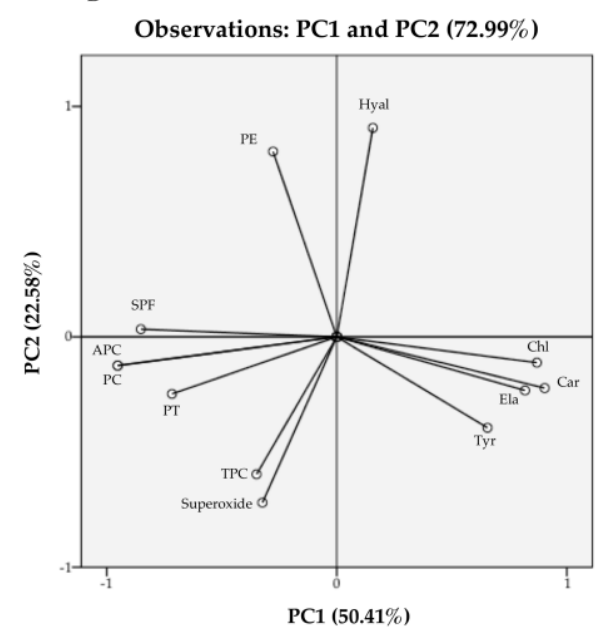

Figure 3. Projection of cyanobacteria extracts (A) [variables: Nodosilinea nodulosa LEGE 06104 (LEGE 06104W and LEGE 06104A), Leptolyngbya cf. ectocarpi LEGE 11479 (LEGE 11479W and LEGE 11479A), Cephalothrix lacustris LEGE 15493 (LEGE 15493W and LEGE 15493A), and Leptolyngbya boryana LEGE 15486 (LEGE 15486W and LEGE 15486A), where "W" refer to aqueous extracts and " $\mathrm{A}$ " to acetone extracts] and loadings (B) by chemical composition and bioactivities [variables: total phenolic content (TPC), total proteins (PT), carotenoids (Car), chlorophyll a (Chl), radical scavenging activity (Superoxide), hyaluronidase (Hyal), elastase (Ela), tyrosinase (Tyr), phycocyanin (PC), phycoerythrin (PE), allophycocyanin (APC), SPF at $1000 \mu \mathrm{g} / \mathrm{mL}$ (SPF)] into the plane composed by the principal components PC1 and PC2 containing $72.99 \%$ of the total variance.

According to Figure 3B, G1 is chemically distinct from the other samples due to the PE content; Cephalothrix lacustris LEGE 15493, Leptolyngbya boryana LEGE 15486, and Nodosilinea nodulosa LEGE 06104 water extracts are grouped according to their content in PC, APC, and total proteins (G2), while all the acetone extracts are found in the same group (G3) due to their content in carotenoids, and chlorophyll $a$ and its derivatives. The compounds beyond the enzymatic activities are displayed, with the planes formed with the PC1 positive axis (Figure 3B). It can be observed that samples with higher contents in chlorophyll $a$ and carotenoids are closely related with elastase and tyrosinase inhibition. This is demonstrated by the strong positive correlation between carotenoids and elastase $(0.725, p<0.01)$ and tyrosinase $(0.782, p<0.01)$ inhibition, with similar observations between chlorophyll $a$ and the same enzymes $(0.702, p<0.01$ and $0.519, p<0.05$, respectively). On the other hand, hyaluronidase inhibition is more correlated with PE content (Figure 3B), with a significant positive correlation between the values $(0.784, p<0.01)$. The compounds responsible for the radical scavenging activity of the extracts are displayed, with the planes formed with the PC1 negative axis. The closest correlation is observed for TPC $(0.567, p<0.05)$; other compounds such as total proteins, PC, and APC also contribute to the activity, although to a lower extent (Figure 3B). Regarding the SPF, there is a close correlation between the activity of the extracts and their PBP content, mainly APC $(0.835, p<0.01)$ and PC $(0.838$, $p<0.01$ ), which points to these compounds as predominantly responsible for blocking 
UV-B radiation. The total protein content also contributed to this biological activity $(0.670$, $p<0.01)$, with the lowest contribution being observed for PE $(0.210, p>0.05)$. In general, the PCA analysis allowed the grouping of extracts according to the biological activities displayed in the field of skin aging, leading to the conclusion that acetone extracts are more effective in inhibiting enzymes responsible for the degradation of the dermal matrix and loss of skin structure, while aqueous extracts are more effective in scavenging free radicals and protecting skin from the deleterious effects of UV radiation.

As far as we know, this is the first time that a relationship between the chemical composition and biological activities of extracts from these cyanobacteria strains has been established.

\section{Materials and Methods}

\subsection{Cyanobacteria Biomass Production}

Four filamentous cyanobacterial strains, Cephalothrix lacustris LEGE 15493 and Leptolyngbya boryana LEGE 15486, from Brazilian freshwater ecosystems, and Leptolyngbya cf. ectocarpi LEGE 11479 and Nodosilinea nodulosa LEGE 06104, from Portuguese marine ecosystems, were used in this study. The strains were maintained in the Blue Biotechnology and Ecotoxicology Culture Collection (LEGE CC) at the Interdisciplinary Center of Marine and Environmental Research (CIIMAR). For biomass production purposes, a scale-up culture scheme was set, starting with $40 \mathrm{~mL}$ under laboratory-controlled conditions, sequentially scaled up to $4 \mathrm{~L}$. The strains were grown in Z8 medium [53], supplemented with $10 \mu \mathrm{g} / \mathrm{L}$ vitamin $\mathrm{B} 12$ and $25 \mathrm{~g} / \mathrm{L} \mathrm{NaCl}$ for marine strains. Cultures were maintained at $25^{\circ} \mathrm{C}$, with a light intensity of $10 \mu \mathrm{mol}$ photons $\mathrm{m}^{-2} \mathrm{~s}^{-1}$, and with a photoperiod of $14 \mathrm{~h}$ light:10 h dark. The fresh biomass was collected after 120 or 150 days of growth (depending on the strain) via filtration, and frozen, freeze-dried, and stored at $-20^{\circ} \mathrm{C}$ until extract preparation.

\subsection{Extracts Preparation}

Two different extracts were sequentially prepared from each strain: acetone and aqueous. First, the acetone extract was prepared, using $2 \mathrm{~g}$ of dry biomass. The biomass was suspended in acetone and extracted for $10 \mathrm{~min}$ in an ultrasonic bath (Fisherbrand ${ }^{\circledR}$ FB15053, Loughborough, UK). After the acetone extraction, the resulting pellet was left to dry in the fume hood, and then extracted with $70 \mathrm{~mL}$ of distilled water, following the same procedure. Cell debris was removed by centrifugation at 10,000× $g$ Gs during 5 min at $4{ }^{\circ} \mathrm{C}$, in a HERAUS Megafuge ${ }^{\mathrm{TM}} 16 \mathrm{R}$ microcentrifuge (Thermo Scientific ${ }^{\mathrm{TM}}$, Waltham, MA, USA). Supernatants from each extraction were evaporated under reduced pressure (BUCHI R-210 Rotary Evaporator) (acetone extract), or frozen and lyophilized (aqueous extract). Extraction with the corresponding supernatant was repeated 3 times. The dry extracts were kept at $-20^{\circ} \mathrm{C}$ until further chemical and biological analysis.

\subsection{Cell Assays}

\subsubsection{Cell Culture}

Human keratinocytes HaCAT (ATCC), mouse fibroblasts 3T3L1 (ATCC), and human endothelial cells hCMEC (provided by Dr. P. O. Couraud (INSERM)) were used for cytotoxicity evaluation. Cell lines were cultured in Dulbecco's Modified Eagle Medium (DMEM GlutaMAX ${ }^{\mathrm{TM}}$, Gibco, Glasgow, UK), supplemented with 10\% (v/v) fetal bovine serum (Gibco), 1\% penicillin-streptomycin (Pen-Strep $100 \mathrm{IU} / \mathrm{mL}$ and $10 \mathrm{mg} / \mathrm{mL}$, respectively) (Gibco) and 0.1\% Amphotericin B (Gibco). Cell maintenance and assays were performed at $37{ }^{\circ} \mathrm{C}$ in a $5 \% \mathrm{CO}_{2}$ humidified atmosphere, and the culture medium was renewed every two days. At 80-90\% cell confluence, adherent cells were washed with phosphate-buffered saline (PBS, Gibco), detached with TrypLEX express enzyme $(1 \times)$ (Gibco), passed for maintenance, and seeded for the planned assays. 


\subsubsection{Cytotoxicity-MTT Assay}

Cellular viability was evaluated by the reduction in the 3-(4,5-dimethylthiazole-2-yl)2,5-diphenyltetrazolium bromide (MTT, Sigma-Aldrich, Germany) assay, as previously reported [26]. All cell lines (endothelial cells, fibroblasts, and keratinocytes) were seeded in 96well plates, at a density of $1.0 \times 10^{5}$ cells $/ \mathrm{mL}, 3.3 \times 10^{4}$ cells $/ \mathrm{mL}$, and $2.5 \times 10^{4}$ cells $/ \mathrm{mL}$, respectively. After $24 \mathrm{~h}$ of cell adhesion, the culture medium was removed, and the cells were exposed for 24 and $48 \mathrm{~h}$ to fresh medium containing the different cyanobacteria extracts in five serial concentrations, from 12.5 to $200 \mu \mathrm{g} / \mathrm{mL}$. For the acetone extracts, stock solutions were prepared in dimethyl sulfoxide (DMSO) (Gibco), and diluted with DMEM prior to cells' exposure so that the maximum DMSO concentration did not exceed $1 \%$. Aqueous extracts were prepared in PBS and diluted with DMEM prior to cells' exposure. The negative control was PBS, and the control for cell death was DMSO $20 \%$. After incubation, the MTT cytotoxicity assay was performed. Briefly, $20 \mu \mathrm{L}$ of MTT solution was added to each well and incubated at $37^{\circ} \mathrm{C}$ for $3 \mathrm{~h}$. Following incubation, the medium was carefully removed, and the purple-colored formazan salts were dissolved in DMSO. The absorbance was read at $550 \mathrm{~nm}$ with a Synergy HT multi-detection microplate reader (Biorek, Bad Friedrichshall, Germany) operated by GEN5 ${ }^{\mathrm{TM}}$ software. The assay was run in quadruplicate and averaged. For reproducibility, each assay was independently repeated at least three times. Cytotoxicity was expressed as the percentage of cell viability, considering $100 \%$ viability in the solvent control.

\subsection{Chemical Profiling of Cyanobacteria Extracts}

3.4.1. Total Phenolic Content (TPC)

To determine the TPC of the extracts, a colorimetric assay was used, based on the Folin-Ciocalteu methodology [54] with slight modifications. The acetone extracts were solubilized in DMSO, and the aqueous extracts in water. Briefly, $25 \mu \mathrm{L}$ of each extract $(10 \mathrm{mg} / \mathrm{mL}$ ) was completely mixed with $25 \mu \mathrm{L}$ of Folin-Ciocalteu reagent (Sigma-Aldrich), $200 \mu \mathrm{L}$ of $\mathrm{Na}_{2} \mathrm{CO}_{3}$ solution, and $500 \mu \mathrm{L}$ of deionized water. For the blank, the FolinCiocalteu reagent was replaced by deionized water. The absorbance of the colored product formed was measured at $725 \mathrm{~nm}$, using a Synergy HT Multi-detection microplate reader (Biotek, Bad Friedrichshall, Germany) operated via GEN5 ${ }^{\mathrm{TM}}$ software. Standard curves for TPC quantification were obtained using seven concentrations of gallic acid (GA) $(0.025$ to $0.5 \mathrm{mg} / \mathrm{mL})$, prepared in the same solvent as the extracts to be tested $(y=2.097 x+0.01560$, $R^{2}=0.9989$, for acetone, and $y=2.204 x+0.01401, R^{2}=0.9982$, for water, where " $y$ " refers to the absorbance and " $x$ " refers to the concentration). Three independent determinations were carried out in duplicate. Total phenolic content was expressed as $\mu \mathrm{g}$ GA equivalents (GAE) per mg of dry extract.

\subsubsection{Total Proteins}

The total protein concentration was determined using the BCA protein assay kit (\#23227, Thermo-Scientific). Aqueous extracts were prepared in water, while acetone extracts were prepared in DMSO. Briefly, in a 96-well plate, $25 \mu \mathrm{L}$ of each extract $(1 \mathrm{mg} / \mathrm{mL})$ was mixed with $200 \mu \mathrm{L}$ of the working reagent. The absorbance was measured at $562 \mathrm{~nm}$, using a Synergy HT Multi-detection microplate reader (Biotek, Bad Friedrichshall, Germany) operated via GEN5 ${ }^{\mathrm{TM}}$ software. A standard curve $\left(y=-126.87 x^{3}+547.73 x^{2}+483.85 x\right.$ $-10.017 ; R^{2}=0.999$, and $y=162.87 x^{3}-248.51 x^{2}+932.13 x-11.715 ; R^{2}=0.999$, where " $y$ " refers to the absorbance and " $x$ " refers to the concentration) was obtained for each extract, using nine concentrations of albumin (BSA) $(25$ to $2000 \mu \mathrm{g} / \mathrm{mL})$ to quantify the proteins. Three independent experiments were carried out in triplicate. The total protein content was expressed as $\mu \mathrm{g}$ of bovine serum albumin (BSA) equivalents per mg of dry extract.

\subsubsection{Pigments}

The pigments present in both aqueous and acetone extracts were quantified spectrophotometrically. Chlorophyll $a$ and its derivatives were quantified using a calibration 
curve obtained with the commercial standard (Sigma-Aldrich): $y=8.0791 x-0.0022$ $\left(\mathrm{R}^{2}=0.996\right)$, where " $y$ " refers to the absorbance and " $x$ " refers to the concentration. Total carotenoids were quantified as $\beta$-carotene (Sigma-Aldrich), through its calibration curve $\left(y=17.133 x+0.0099 ; \mathrm{R}^{2}=0.990\right.$, where " $y$ " refers to the absorbance and " $x$ " refers to the concentration). Total carotenoid concentration was expressed as $\mu \mathrm{g}$ of $\beta$-carotene per $\mathrm{mg}$ of dry extract. Calibration curves for both standards were obtained using five different concentrations $(0.001$ to $0.025 \mathrm{mg} / \mathrm{mL})$. The spectrophotometric determinations were performed in 96-well plates, at $450 \mathrm{~nm}$ for $\beta$-carotene and $663 \mathrm{~nm}$ for chlorophyll $a$, using a Synergy HT Multi-detection microplate reader (Biotek, Bad Friedrichshall, Germany) operated via GEN5 ${ }^{\mathrm{TM}}$ software.

PBP content was determined spectrophotometrically by measuring the absorbances of the aqueous extracts at different wavelengths $(562,615$, and $645 \mathrm{~nm})$, and applying the corresponding formulas, as previously described by Pagels et al. [34]:

$$
\begin{gathered}
\text { Phycocyanin }(P C)=\frac{A_{615 n m}-0.474 \times A_{652 n m}}{5.34} \\
\text { Allophycocyanin }(A P C)=\frac{A_{652 n m}-0.208 \times A_{615 n m}}{5.09} \\
\text { Phycoerythrin }(P E)=\frac{A_{562 n m}-2.41 \times P C-0.849 \times A P C}{9.62}
\end{gathered}
$$

Aqueous extracts were resuspended to a final concentration of $0.5 \mathrm{mg} / \mathrm{mL}$. The experiment was carried out in triplicate, and the results were expressed in $\mu \mathrm{g} / \mathrm{mg}$ of dry extract.

\subsection{Biological Activities}

\subsubsection{Superoxide Anion Radical $\left(\mathrm{O}_{2}{ }^{\bullet-}\right)$ Scavenging}

The free radical scavenging assay of $\mathrm{O}_{2}{ }^{\bullet-}$ was performed to evaluate the antioxidant potential of the cyanobacteria extracts, according to Barbosa and co-workers [55], with minor modifications. The aqueous extracts were prepared in water, while acetone extracts were prepared in DMSO. Five serial dilutions were prepared for each extract and tested in order to evaluate the extracts' behavior and IC values. All reagents were dissolved in phosphate buffer $(19 \mu \mathrm{M}, \mathrm{pH} 7.4)$. A volume of $50 \mu \mathrm{L}$ of each dilution was mixed with $50 \mu \mathrm{L}$ of $166 \mu \mathrm{M} \beta$-nicotinamide adenine dinucleotide reduced form (NADH) solution and $150 \mu \mathrm{L}$ of $43 \mu \mathrm{M}$ nitrotetrazolium blue chloride (NBT) in a 96-well plate. After the addition of $50 \mu \mathrm{L}$ of $2.7 \mu \mathrm{M}$ phenazine methosulphate (PMS), the radical scavenging activity of the samples was monitored with a Synergy HT Multi-detection microplate reader (Biotek, Bad Friedrichshall, Germany) operated via GEN5 ${ }^{\mathrm{TM}}$ software, in kinetic function, at room temperature for $2 \mathrm{~min}$ at $562 \mathrm{~nm}$. Three independent assays were performed in triplicate. GA was used as a positive control. The results were expressed as the percentage of radical scavenging in comparison to the untreated control. The results for the calculated IC values were expressed as the mean $\pm \mathrm{SD}(\mu \mathrm{g} / \mathrm{mL})$ of at least three independent assays performed in duplicate. The IC values and corresponding dose-response curves were calculated with Graphpad Prism ${ }^{\circledR}$ software (San Diego, CA, USA; version 9, for MacOS).

\subsubsection{Hyaluronidase Inhibition}

The hyaluronidase inhibition assay was slightly modified from that proposed by Ferreres et al. [56]. Briefly, $25 \mu \mathrm{L}$ of each extract $(9 \mathrm{mg} / \mathrm{mL}), 175 \mu \mathrm{L}$ hyaluronic acid (HA) $(0.7 \mathrm{mg} / \mathrm{mL})$, and $25 \mu \mathrm{L}$ of hyaluronidase (HAase) $(900 \mathrm{U} / \mathrm{mL}$ in $\mathrm{NaCl} 0.9 \%)$ were mixed in a reaction tube. Aqueous extracts were prepared in water, and acetone extracts were prepared in DMSO. After $30 \mathrm{~min}$ of incubation at $37^{\circ} \mathrm{C}$, the reaction was stopped by the addition of $25 \mu \mathrm{L}$ of di-sodium tetraborate ( $0.8 \mathrm{M}$ in water), followed by incubation for $3 \mathrm{~min}$ at $90^{\circ} \mathrm{C}$ in a water bath. The reaction tubes were cooled to room temperature before $375 \mu \mathrm{L}$ of DMAB [4-(Dimethylamino)benzaldehyde] solution was added. After 20 min of incubation at $37^{\circ} \mathrm{C}$, the absorbance of the colored product formed was measured at $560 \mathrm{~nm}$, 
in a Synergy HT Multi-detection microplate reader (Biotek, Bad Friedrichshall, Germany) operated via GEN5 ${ }^{\mathrm{TM}}$ software. The negative control was performed in the absence of extract. Disodium cromoglycate (DSCG) was used as a positive control.

Three independent assays were performed in triplicate, and the results were expressed as the percentage of enzyme inhibition in comparison to the untreated control.

\subsubsection{Elastase Inhibition}

Porcine pancreatic elastase inhibition assay was performed according to Mota and co-workers [57] with slight modifications. Aqueous extracts were prepared in water, while acetone extracts were prepared in DMSO. Briefly, in a 96-well plate, $50 \mu \mathrm{L}$ of extract was mixed with $90 \mu \mathrm{L}$ of HEPES buffer $(0.1 \mathrm{M}), 10 \mu \mathrm{L}$ of N-succinyl-Ala-Ala-Ala p-nitroanilide substrate $(100 \mu \mathrm{M}), 70 \mu \mathrm{L}$ of acetate buffer $(200 \mathrm{mM})$, and $30 \mu \mathrm{L}$ of elastase $(1 \mathrm{U} / \mathrm{mL})$. The plate was incubated at $37^{\circ} \mathrm{C}$ for $10 \mathrm{~min}$, and the absorbance of the reaction product was measured at $405 \mathrm{~nm}$, in a Synergy HT Multi-detection microplate reader (Biotek, Bad Friedrichshall, Germany) operated via GEN5 ${ }^{\mathrm{TM}}$. The negative control was performed in the absence of extract, and ascorbic acid was used as a positive control. Three independent assays were performed in triplicate. The results were expressed as the percentage of enzyme inhibition in comparison to the untreated control.

\subsubsection{Tyrosinase Inhibition}

The tyrosinase inhibition assay was performed according to Adhikari et al. [58] with slight modifications. Briefly, in a 96-well plate, $20 \mu \mathrm{L}$ of each extract was mixed with $100 \mu \mathrm{L}$ of tyrosinase ( $30 \mathrm{U} / \mathrm{mL}$ in phosphate buffer). Aqueous extracts were prepared in water, while acetone extracts were prepared in DMSO. The mixture was incubated at $30^{\circ} \mathrm{C}$ for $8 \mathrm{~min}$. Then, $80 \mu \mathrm{L}$ of L-DOPA (L-3,4-dihydroxyphenylalanine) solution $(2.5 \mathrm{mM}$ in phosphate buffer) was added, and the absorption (T0, absorbance at time "zero") was immediately measured with a Synergy HT Multi-detection microplate reader (Biotek, Bad Friedrichshall, Germany) operated via GEN5 ${ }^{\mathrm{TM}}$ software, at $475 \mathrm{~nm}$. The determination of the absorbance at $\mathrm{T} 0$ (before the reaction product was formed) allowed the elimination of possible interferences due to the natural color of the extracts under study. After $8 \mathrm{~min}$ of incubation at $30^{\circ} \mathrm{C}$, the absorbance was measured again (T8). The percentage of tyrosinase inhibition in the presence of cyanobacteria extracts was calculated in comparison to the untreated (negative) control, where the difference between the absorbances (T8-T0) corresponds to $100 \%$ of enzyme activity. The negative control was performed in the absence of extract, and kojic acid was used as a positive control. Three independent assays were performed in triplicate. The results were expressed as the percentage of enzyme inhibition in comparison to the untreated control.

\subsubsection{Sun Protection Factor (SPF)}

The in vitro sun protector factor was determined according to Rohr and co-workers [59] with slight modifications. Aqueous extracts were prepared in water, while acetone extracts were prepared in acetone. Briefly, the absorbance of $2 \mathrm{~mL}$ of each extract (200 and $1000 \mu \mathrm{g} / \mathrm{mL}$ ), was measured in a spectrophotometer (from 290 to $320 \mathrm{~nm}, 5 \mathrm{in} 5 \mathrm{~nm}$ ). The SPF was calculated using the formula proposed by Mansur [60]:

$$
S P F_{\text {spectrophotometric }}=C F \times \sum_{290}^{320} E E(\lambda) \times I(\lambda) \times A b s(\lambda)
$$

where $E E(\lambda)$ is the erythemal effect spectrum, $I(\lambda)$ is the solar intensity spectrum, $A b s(\lambda)$ is the absorbance of extract, and $C F$ is the correction factor (28) determined using a commercial sunscreen with a known SFP value of 30 . 


\subsection{Statistical Analysis}

Statistical analysis was performed using IBM SPSS statistics software (version 23.0 for MacOS, IBM Corporation, New York, NY, USA, 2015). Data were analyzed for normality and the homogeneity of variances by Kolmogorov-Smirnov and Leven's tests, then submitted to a one-way ANOVA using a Tukey's HSD (honest significant difference) as a post-hoc test, or to an unpaired $t$-test. A Pearson correlation test was used to compare the normalized expression data between the chemical profiles and biological activities of cyanobacteria extracts.

\subsection{Principal Component Analysis (PCA)}

PCA was used to transform a number of potentially correlated variables into a number of relatively independent variables, able to be ranked based on their contribution to explaining the variation of the whole data set [61]. The relatively important components of high-dimensional patterns can be successfully identified. The original high-dimensional data can be mapped onto a lower dimensional space, and therefore the complexity of a high-dimensional pattern classification problem is greatly reduced [62]. For the present study, pattern recognition based on PCA was performed using IBM SPSS statistics software (version 23.0 for MacOS, IBM Corporation, New York, NY, USA, 2015). The data matrix consisted on the metabolites present in the aqueous and acetone extracts of the four cyanobacteria strains, and their activity at the highest concentration tested.

\section{Conclusions}

The biological activity displayed by the cyanobacteria extracts analyzed herein proved to be clearly correlated. According to the presence of bioactive PBPs, the aqueous extracts were the most effective for UV protection which, together with their radical scavenging capacity, suggests them as promising ingredients to be used in anti-aging formulations aimed at preventing skin aging exacerbated by external factors. On the other hand, the acetone extracts proved more effective in inhibiting the activity of enzymes responsible for the degradation of the dermal matrix and loss of skin structure, thus being more suitable for age-related skin aging. The sequential extraction scheme we propose could prove advantageous, allowing the obtainment of chemically different bioactive extracts through the monetization of cyanobacteria biomass, making the process more sustainable and economically attractive. Altogether, cyanobacteria extracts proved worthy of further exploitation in the field of skin aging, targeting the search for natural, safe, and sustainable ingredients for cosmetic formulations.

Supplementary Materials: The following supporting information can be downloaded at: https: //www.mdpi.com/article/10.3390/md20030183/s1: Figure S1: Keratinocyte (HaCAT) viability after 24 and $48 \mathrm{~h}$ of incubation with cyanobacteria aqueous (A-D) and acetone (E-H) extracts. (A,E) Cephalothrix lacustris LEGE 15493, (B,F) Nodosilinea nodulosa LEGE 06104, (C,G) Leptolyngbya cf. ectocarpi LEGE 11479, and (D,H) Leptolyngbya boryana LEGE 15486. Results are expressed as the percentage of MTT reduction vs. the untreated control. DMSO (20\%) represents the positive control. Results are expressed as the mean \pm SD of at least three independent assays, performed in quadruplicate. Statistical differences at ${ }^{*} p<0.05,{ }^{* *} p<0.01,{ }^{* * *} p<0.001,{ }^{* * * *} p<0.0001$ (One way ANOVA, Tuckey HSD multiple comparisons test). Figure S2: Fibroblast (3T3L1) viability after 24 and $48 \mathrm{~h}$ of incubation with cyanobacteria aqueous (A-D) and acetone (E-H) extracts. (A,E) Cephalothrix lacustris LEGE 15493, (B,F) Nodosilinea nodulosa LEGE 06104, (C,G) Leptolyngbya cf. ectocarpi LEGE 11479, and (D,H) Leptolyngbya boryana LEGE 15486. Results are expressed as the percentage of MTT reduction vs. the untreated control. DMSO (20\%) represents the positive control. Results are expressed as the mean $\pm \mathrm{SD}$ of at least three independent assays, performed in quadruplicate. Statistical differences at ${ }^{*} p<0.05,{ }^{* *} p<0.01,{ }^{* * *} p<0.001,{ }^{* * * *} p<0.0001$ (One way ANOVA, Tuckey HSD multiple comparisons test). Figure S3: Endothelial cell (hCMEC) viability after 24 and $48 \mathrm{~h}$ of incubation with cyanobacteria aqueous (A-D) and acetone (E-H) extracts. (A,E) Cephalothrix lacustris LEGE 15493, (B,F) Nodosilinea nodulosa LEGE 06104, (C,G) Leptolyngbya cf. ectocarpi LEGE 11479, and (D,H) Leptolyngbya boryana LEGE 15486. Results are expressed as a percentage of MTT reduction 
vs. the untreated control. DMSO (20\%) represents the positive control. Results are expressed as the mean \pm SD of at least three independent assays, performed in quadruplicate. Statistical differences at ${ }^{*} p<0.05,{ }^{* *} p<0.01,{ }^{* * *} p<0.001,{ }^{* * * *} p<0.0001$ (one way ANOVA, Tuckey HSD multiple comparisons test).

Author Contributions: Conceptualization, G.L.; methodology, R.F. and J.M.; data analysis, R.F., J.M., R.M. and G.L.; investigation, R.F. and J.M.; writing-original draft preparation, G.L. and R.F.; writing-review and editing, G.L., R.F., J.M., R.M. and V.V.; supervision, G.L.; funding acquisition, V.V. All authors have read and agreed to the published version of the manuscript.

Funding: This research was partially supported by AlgaValor-MicroALGAs: integrated production and valorization of biomass and its various applications-SI I\&DT no 352234-supported by the Portugal 2020 project through the European Regional Development Fund, and by the strategic funding-UIDB/04423/2020 and UIDP/04423/2020—of CIIMAR.

Institutional Review Board Statement: Not applicable.

Data Availability Statement: Not applicable.

Acknowledgments: Graciliana Lopes thanks the Portuguese Foundation for Science and Technology (FCT) for the financial support for her work contract through the Scientific Employment Stimulus-Individual Call (CEECIND/01768/2021). Janaína Morone is grateful to the FCT for grant no. UI/BD/150903/2021. The authors acknowledge Mariana Barbosa, from the Applied Biomolecular Sciences Unit (UCIBIO), Department of Life Sciences, NOVA School of Science and Technology (FCT NOVA), University of Lisbon, whose suggestions and theoretical support helped to improve and clarify this manuscript.

Conflicts of Interest: The authors declare no conflict of interest. The funders had no role in the design of the study; in the collection, analyses, or interpretation of data; in the writing of the manuscript, or in the decision to publish the results.

\section{References}

1. Favas, R.; Morone, J.; Martins, R.; Vasconcelos, V.; Lopes, G. Cyanobacteria and microalgae bioactive compounds in skin-ageing: Potential to restore extracellular matrix filling and overcome hyperpigmentation. J. Enzym. Inhib. Med. Chem. 2021, 36, 1829-1838. [CrossRef]

2. Albrecht, S.; Jung, S.; Müller, R.; Lademann, J.; Zuberbier, T.; Zastrow, L.; Meinke, M.C. Skin type differences in solar simulated radiation-induced oxidative stress. Br. J. Dermatol. 2018, 180, 597-603. [CrossRef] [PubMed]

3. Lourith, N.; Kanlayavattanakul, M. Biopolymeric agents for skin wrinkle treatment. J. Cosmet. Laser Ther. 2016, 18, 301-310. [CrossRef] [PubMed]

4. Deniz, F.S.S.; Salmas, R.E.; Emerce, E.; Cankaya, I.I.T.; Yusufoglu, H.S.; Orhan, I.E. Evaluation of collagenase, elastase and tyrosinase inhibitory activities of Cotinus coggygria Scop. through in vitro and in silico approaches. S. Afr. J. Bot. 2020, 132, 277-288. [CrossRef]

5. Makrantonaki, E.; Zouboulis, C.C. Molecular mechanisms of skin aging-State of the art. Mol. Mech. Models Aging 2007, 1119, 40-50. [CrossRef]

6. Pensalfini, M.; Rotach, M.; Hopf, R.; Bielicki, A.; Santoprete, R.; Mazza, E. How cosmetic tightening products modulate the biomechanics and morphology of human skin. Acta Biomater. 2020, 115, 299-316. [CrossRef]

7. Lopes, G.; Silva, M.; Vasconcelos, V. The Pharmacological Potential of Cyanobacteria; Elsevier: Amsterdam, The Netherlands, 2022; ISBN 9780128214923.

8. Singh, S.K.; Kaur, R.; Bansal, A.; Kapur, S.; Sundaram, S. Biotechnological exploitation of cyanobacteria and microalgae for bioactive compounds. Biotechnol. Prod. Bioact. Compd. 2020, 11, 221-259. [CrossRef]

9. Morone, J.; Alfeus, A.; Vasconcelos, V.; Martins, R. Revealing the potential of cyanobacteria in cosmetics and cosmeceuticals-A new bioactive approach. Algal Res.-Biomass Biofuels Bioprod. 2019, 41, 101541. [CrossRef]

10. Morone, J.; Lopes, G.; Oliveira, B.; Vasconcelos, V.; Martins, R. Cyanobacteria in cosmetics: A natural alternative for antiaging ingredients. In The Pharmacological Potential of Cyanobacteria; Lopes, G., Silva, M., Vasconcelos, V., Eds.; Academic Press: Cambridge, MA, USA, 2022; pp. 257-286, ISBN 9780128214923. [CrossRef]

11. Pagels, F.; Guedes, A.; Vasconcelos, V.; Lopes, G. Anti-inflammatory compounds from cyanobacteria. In The Pharmacological Potential of Cyanobacteria; Lopes, G., Silva, M., Vasconcelos, V., Eds.; Academic Press: Cambridge, MA, USA, 2022; pp. 81-105, ISBN 9780128214923. [CrossRef]

12. Assunção, J.; Amaro, H.; Malcata, F.; Guedes, A. Cyanobacterial pigments: Photosynthetic function and biotechnological purposes. In The Pharmacological Potential of Cyanobacteria; Academic Press: Cambridge, MA, USA, 2022; pp. 201-256. 
13. Nowruzi, B.; Sarvari, G.; Blanco, S. The cosmetic application of cyanobacterial secondary metabolites. Algal Res.-Biomass Biofuels Bioprod. 2020, 49, 10195. [CrossRef]

14. Pagels, F.; Guedes, A.C.; Amaro, H.M.; Kijjoa, A.; Vasconcelos, V. Phycobiliproteins from cyanobacteria: Chemistry and biotechnological applications. Biotechnol. Adv. 2019, 37, 422-443. [CrossRef]

15. Jerez-Martel, I.; Garcia-Poza, S.; Rodriguez-Martel, G.; Rico, M.; Afonso-Olivares, C.; Gomez-Pinchetti, J.L. Phenolic Profile and Antioxidant Activity of Crude Extracts from Microalgae and Cyanobacteria Strains. J. Food Qual. 2017, 2017, 2924508. [CrossRef]

16. Gao, X.; Jing, X.; Liu, X.F.; Lindblad, P. Biotechnological production of the sunscreen pigment scytonemin in cyanobacteria: Progress and strategy. Mar. Drugs 2021, 19, 129. [CrossRef] [PubMed]

17. Tarasuntisuk, S.; Patipong, T.; Hibino, T.; Waditee-Sirisattha, R.; Kageyama, H. Inhibitory effects of mycosporine-2-glycine isolated from a halotolerant cyanobacterium on protein glycation and collagenase activity. Lett. Appl. Microbiol. 2018, 67, 314-320. [CrossRef] [PubMed]

18. Keller, L.; Canuto, K.M.; Liu, C.X.; Suzuki, B.M.; Almaliti, J.; Sikandar, A.; Naman, C.B.; Glukhov, E.; Luo, D.M.; Duggan, B.M.; et al. Tutuilamides A-C: Vinyl-chloride-containing cyclodepsipeptides from marine cyanobacteria with potent elastase inhibitory properties. ACS Chem. Biol. 2020, 15, 751-757. [CrossRef] [PubMed]

19. Yamaguchi, Y.; Koketsu, M. Isolation and analysis of polysaccharide showing high hyaluronidase inhibitory activity in Nostochopsis lobatus MAC0804NAN. J. Biosci. Bioeng. 2016, 121, 345-348. [CrossRef]

20. CODIF. Phormiskin Bioprotech G. Available online: http://www.codif-tn.com/en/principesactifs/phormiskin-bioprotech-g/ (accessed on 28 September 2021).

21. Tracy, L.E.; Minasian, R.A.; Caterson, E.J. Extracellular Matrix and Dermal Fibroblast Function in the Healing Wound. Adv. Wound Care 2016, 5, 119-136. [CrossRef]

22. Sumpio, B.E.; Timothy Riley, J.; Dardik, A. Cells in focus: Endothelial cell. Int. J. Biochem. Cell Biol. 2002, 34, 1508-1512. [CrossRef]

23. Barker, J.N.W.N.; Griffiths, C.E.M.; Nickoloff, B.J.; Mitra, R.S.; Dixit, V.M.; Nickoloff, B.J. Keratinocytes as initiators of inflammation. Lancet 1991, 337, 211-214. [CrossRef]

24. Barbieri, J.S.; Seykora, J. Pathobiology of Human Disease. Encycl. Dis. Mech. 2014, 11, 2588-2608. [CrossRef]

25. Galanakis, C.M.; Goulas, V.; Tsakona, S.; Manganaris, G.A.; Gekas, V. A Knowledge Base for The Recovery of Natural Phenols with Different Solvents. Int. J. Food Prop. 2013, 16, 382-396. [CrossRef]

26. Morone, J.; Lopes, G.; Preto, M.; Vasconcelos, V.; Martins, R. Exploitation of filamentous and picoplanktonic cyanobacteria for cosmetic applications: Potential to improve skin structure and preserve dermal matrix components. Mar. Drugs 2020, 18, 486. [CrossRef] [PubMed]

27. Lopes, G.; Clarinha, D.; Vasconcelos, V. Carotenoids from cyanobacteria: A biotechnological approach for the topical treatment of psoriasis. Microorganisms 2020, 8, 302. [CrossRef] [PubMed]

28. Trabelsi, L.; Mnari, A.; Abdel-Daim, M.M.; Abid-Essafi, S.; Aleya, L. Therapeutic properties in Tunisian hot springs: First evidence of phenolic compounds in the cyanobacterium Leptolyngbya sp. biomass, capsular polysaccharides and releasing polysaccharides. BMC Complement. Altern. Med. 2016, 16, 515. [CrossRef] [PubMed]

29. Pumas, C.; Vacharapiyasophon, P.; Peerapornpisal, Y.; Leelapornpisid, P.; Boonchum, W.; Ishii, M.; Khanongnuch, C. Thermostablility of phycobiliproteins and antioxidant activity from four thermotolerant cyanobacteria. Phycol. Res. 2011, 59, 166-174. [CrossRef]

30. Hossain, M.F.; Ratnayake, R.R.; Meerajini, K.; Wasantha Kumara, K.L. Antioxidant properties in some selected cyanobacteria isolated from fresh water bodies of Sri Lanka. Food Sci. Nutr. 2016, 4, 753-758. [CrossRef]

31. González López, C.V.; García, M.d.C.C.; Fernández, F.G.A.; Bustos, C.S.; Chisti, Y.; Sevilla, J.M.F. Protein measurements of microalgal and cyanobacterial biomass. Bioresour. Technol. 2010, 101, 7587-7591. [CrossRef] [PubMed]

32. Vega, J.; Bonomi-Barufi, J.; Gómez-Pinchetti, J.L.; Figueroa, F.L. Cyanobacteria and Red Macroalgae as Potential Sources of Antioxidants and UV Radiation-Absorbing Compounds for Cosmeceutical Applications. Mar. Drugs 2020, 18, 659. [CrossRef]

33. Kokabi, M.; Yousefzadi, M.; Soltani, M.; Arman, M. Effects of different UV radiation on photoprotective pigments and antioxidant activity of the hot-spring cyanobacterium Leptolyngbya cf. fragilis. Phycol. Res. 2019, 67, 215-220. [CrossRef]

34. Pagels, F.; Salvaterra, D.; Amaro, H.M.; Lopes, G.; Sousa-Pinto, I.; Vasconcelos, V.; Guedes, A.C. Bioactive potential of Cyanobium sp. pigment-rich extracts. J. Appl. Phycol. 2020, 32, 3031-3040. [CrossRef]

35. Hemlata; Fatma, T. Screening of Cyanobacteria for Phycobiliproteins and Effect of Different Environmental Stress on Its Yield Bull. Environ. Contam. Toxicol. 2009, 83, 509-515. [CrossRef]

36. Stahl, W.; Sies, H. Antioxidant activity of carotenoids. Mol. Asp. Med. 2003, 24, 345-351. [CrossRef]

37. Amaro, H.; Fernandes, F.; Valentão, P.; Andrade, P.; Sousa-Pinto, I.; Malcata, F.; Guedes, A. Effect of Solvent System on Extractability of Lipidic Components of Scenedesmus obliquus (M2-1) and Gloeothece sp. on Antioxidant Scavenging Capacity Thereof. Mar. Drugs 2015, 13, 6453-6471. [CrossRef] [PubMed]

38. Philips, N.; Auler, S.; Hugo, R.; Gonzalez, S. Beneficial regulation of matrix metalloproteinases for skin health. Enzym. Res. 2011, 2011, 427285. [CrossRef]

39. Maquart, F.X.; Monboisse, J.C. Extracellular matrix and wound healing. Pathol. Biol. 2014, 62, 91-95. [CrossRef] [PubMed]

40. Sin, B.Y.; Kim, H.P. Inhibition of collagenase by naturally-occurring flavonoids. Arch. Pharmacal Res. 2005, $28,1152-1155$. [CrossRef] 
41. Yarkent, C.; Gurlek, C.; Oncel, S.S. Potential of microalgal compounds in trending natural cosmetics: A review. Sustain. Chem. Pharm. 2020, 17, 100304. [CrossRef]

42. Fujitani, N.; Sakaki, S.; Yamaguchi, Y.; Takenaka, H. Inhibitory effects of microalgae on the activation of hyaluronidase. J. Appl. Phycol. 2001, 13, 489-492. [CrossRef]

43. Montalvo, G.E.B.; Thomaz-Soccol, V.; Vandenberghe, L.P.S.; Carvalho, J.C.; Faulds, C.B.; Bertrand, E.; Prado, M.R.M.; Bonatto, S.J.R.; Soccol, C.R. Arthrospira maxima OF15 biomass cultivation at laboratory and pilot scale from sugarcane vinasse for potential biological new peptides production. Bioresour. Technol. 2019, 273, 103-113. [CrossRef]

44. Murakami, M.; Sun, Q.; Ishida, K.; Matsuda, H.; Okino, T.; Yamaguchi, K. Microviridins, elastase inhibitors from the cyanobacterium Nostoc minutum (NIES-26). Phytochemistry 1997, 45, 1197-1202. [CrossRef]

45. Okino, T.; Qi, S.; Matsuda, H.; Murakami, M.; Yamaguchi, K. Nostopeptins A and B, elastase inhibitors from the cyanobacterium Nostoc minutum. J. Nat. Prod. 1997, 60, 158-161. [CrossRef]

46. Okino, T.; Matsuda, H.; Murakami, M.; Yamaguchi, K. New microviridins, elastase inhibitors from the blue-green alga Microcystis aeruginosa. Tetrahedron 1995, 51, 10679-10686. [CrossRef]

47. Zolghadri, S.; Bahrami, A.; Hassan Khan, M.T.; Munoz-Munoz, J.; Garcia-Molina, F.; Garcia-Canovas, F.; Saboury, A.A. A comprehensive review on tyrosinase inhibitors. J. Enzym. Inhib. Med. Chem. 2019, 34, 279-309. [CrossRef] [PubMed]

48. Yabuta, Y.; Hashimoto, E.; Takeuchi, T.; Sakaki, S.; Yamaguchi, Y.; Takenaka, H.; Watanabe, F. Characterization of a Hot Water Extract of an Edible Cyanobacterium Nostochopsis sp. for Use as an Ingredient in Cosmetics. Food Sci. Technol. Res. 2014, 20, 505-507. [CrossRef]

49. Sahin, S.C. The potential of Arthrospira platensis extract as a tyrosinase inhibitor for pharmaceutical or cosmetic applications. S. Afr. J. Bot. 2018, 119, 236-243. [CrossRef]

50. Baumann, L. Skin ageing and its treatment. J. Pathol. 2007, 211, 241-251. [CrossRef]

51. Hossain, M.F.; Bowange, R.W.T.M.R.T.K.; Kumara, K.L.W.; Magana-Arachchi, D.N.; Ratnayake, R.R. First record of cyanobacteria species: Cephalothrix komarekiana, from tropical Asia. Environ. Eng. Res. 2021, 26, 200040. [CrossRef]

52. Torres, A.; Enk, C.D.; Hochberg, M.; Srebnik, M. Porphyra-334, a potential natural source for UVA protective sunscreens. Photochem. Photobiol. Sci. 2006, 5, 432-435. [CrossRef]

53. Kotai, J. Instructions for Preparation of Modified Nutrient Solution Z8 for Algae. Nor. Inst. Water Res. 1972, 11, 5.

54. Folin, O.; Ciocalteu, V. Tyrosine and tryptophane in proteins. J. Biol. Chem. 1927, 627-650. [CrossRef]

55. Barbosa, M.; Fernandes, F.; Carlos, M.J.; Valentão, P.; Andrade, P.B. Adding value to marine invaders by exploring the potential of Sargassum muticum (Yendo) Fensholt phlorotannin extract on targets underlying metabolic changes in diabetes. Algal Res. 2021, 59, 102455. [CrossRef]

56. Ferreres, F.; Lopes, G.; Gil-Izquierdo, A.; Andrade, P.B.; Sousa, C.; Mouga, T.; Valentão, P. Phlorotannin extracts from fucales characterized by HPLC-DAD-ESI-MSn: Approaches to hyaluronidase inhibitory capacity and antioxidant properties. Mar. Drugs 2012, 10, 2766-2781. [CrossRef] [PubMed]

57. Mota, F.A.R.; Pereira, S.A.P.; Araujo, A.R.T.S.; Saraiva, M.L.M.F.S. Evaluation of Ionic Liquids and Ionic Liquids Active Pharmaceutical Ingredients Inhibition in Elastase Enzyme Activity. Molecules 2021, 26, 200. [CrossRef]

58. Adhikari, A.; Devkota, H.P.; Takano, A.; Masuda, K.; Nakane, T.; Basnet, P.; Skalko-Basnet, N. Screening of Nepalese crude drugs traditionally used to treat hyperpigmentation:in vitrotyrosinase inhibition. Int. J. Cosmet. Sci. 2008, 30, 353-360. [CrossRef] [PubMed]

59. Rohr, M.; Klette, E.; Ruppert, S.; Bimzcok, R.; Klebon, B.; Heinrich, U.; Zastrow, L. In vitro Sun Protection Factor: Still a Challenge with No Final Answer. Ski. Pharmacol. Physiol. 2010, 23, 201-212. [CrossRef]

60. Mansur, J.S.; Breder, M.N.R.; Mansur, M.C.A.; Azulay, R.D. Determinação do fator de proteção solar por espectrofotometria. An. Bras. Derm. 1986, 61, 121-124.

61. Xu, J.; Hagler, A. Chemoinformatics and drug discovery. Molecules 2002, 7, 566-600. [CrossRef]

62. Lo, T.C.T.; Jiang, Y.H.; Chao, A.L.J.; Chang, C.A. Use of statistical methods to find the polysaccharide structural characteristics and the relationships between monosaccharide composition ratio and macrophage stimulatory activity of regionally different strains of Lentinula edodes. Anal. Chim. Acta 2007, 584, 50-56. [CrossRef] 